\title{
Estimating of rice crop yield in Thailand using satellite data
}

\author{
J. Nontasiri, J. Dash, and G. Roberts \\ Department of Geography and Environmental Science, University of Southampton, University Road, \\ Southampton, United Kingdom.
}

\begin{abstract}
Rice is the world's major staple food crop occupying over $12 \%$ of global cropland area which produces around 800 million tons. Nearly $90 \%$ of the world's rice is produced and consumed in Asian countries. Therefore, information on agricultural plantation area, yield, and production are essential to ensure food security of nearly 3 billion people. At the moment this information is either lacking in many countries or only available post-harvest, this is too late to input into any effecting policy in a specific year. Therefore, there is a pressing need to provide accurate and reliable yield estimation well ahead of harvest. In this project we explore potential of multi source remote sensing data coupled with crop model to provide country scale yield estimation in Thailand.

For optical sensor, the study utilised Landsat8 OLI/TIRS satellite data to develop common vegetation indexes (VIs) approach to derive essential crop biophysical variables such as Leaf Area Index. This is supplemented with information from microwave sensor such as Sentinel 1 to overcome issues with cloud. At the end, we produced a regular time series of crop biophysical variable across the growing season. These satellite-based estimates were validated with dedicated field campaign in three provinces covering the entire growing season. Initial results suggest a good agreement between the optical/microwave derived crop biophysical variables and ground data. Finally, these will be used as an input to the ORYZA 2000 crop model to adjust the model parameters and develop a high resolution yield prediction.
\end{abstract}

Keywords: Rice, yield estimation, oryza2000, sentinel-1, LANDSAT8 OLI/TIRS, vegetation index, NDVI, EVI, and NDWI.

\section{INTRODUCTION}

Rice is one of the most important crops in the world occupying over $12 \%$ of global cropland area ${ }^{1}$ which produces around 800 million tons $^{2}$. Nearly $90 \%$ of the world's rice is produced and consumed in Asian countries ${ }^{3}$. Rice mostly planted in lowland rice area while some rice areas planted in upland areas. The information on agricultural plantation area, yield, and production are essential to ensure food security of nearly 3 billion people. At the moment, this information is lacking in many countries or only available at post harvesting time, this is too late to input to agricultural policies. Thus, there is a necessary need to provide accurate and reliable of rice yield estimation. This research aims to estimate rice yield in regional level by exploring potential of multi sources of remote sensing data coupled with crop model to provide country scale yield estimation in Thailand.

Chao Phraya River delta which is one of the major rice growing region in Thailand. These agricultural areas mostly located in irrigated area which is support irrigation systems (e.g., irrigation projects and canals) by government and have sufficient water for agricultural activities. Thus, these rice areas have high density planting because farmers can planted rice crop 2-3 times per year. Thus, there are enormous advantages for study the potential of remote sensing in these areas. The study identified the amount and location of sample units which are closely related with rice cultivated areas in Chao Phraya River delta. To prepare representative sub-districts, the study analysed government statistical data of rice cultivated area in year 2016/2017. 


\section{STUDY AREA AND METHODOLOGY}

\subsection{Study area}

Our study area located in Chao Phraya River delta which is included 11 provinces in middle part and main rice cultivation area of Thailand. Due to time and field survey costs limitation, the present study identify three representative provinces in Chao Phraya River delta to collect rice biophysical. Thus, the study identified Phichit (upper delta), Ang Thong (middle delta), and Pathum Thani (lower delta).

In Phichit, there are various categories of irrigation system in area such as main irrigation, support irrigation, and rainfed area. While Ang Thong and Pathum Thani, all of rice areas located in main irrigation system. Thus, Ang Thong and Pathum Thani have sufficient water for agricultural activities during season.

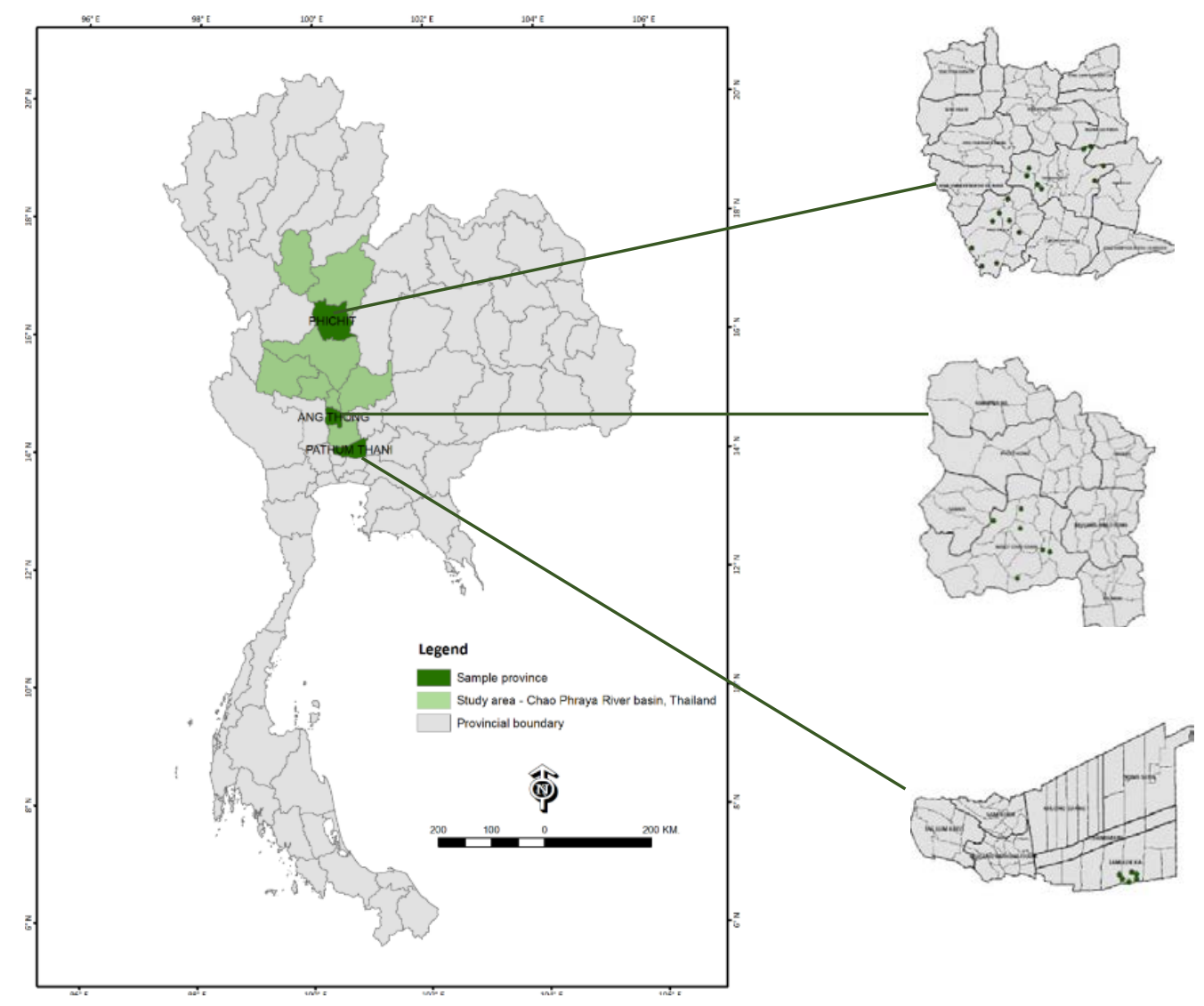

Figure 1. The representative provinces in study area represented in Phichit, Ang Thong, and Pathum Thani.

The total amount of sample units in study area are 28 sample units which were located in Phichit (16 sample units in Pho Tha Le and Ta Pan Hin district), Ang Thong (6 sample units in Wisetchaichan district), and Pathum Thani (6 sample units in Lam Lukka district). There are difference irrigation system in Phichit province thus there are essential to determine the difference among irrigation system. 


\subsection{Rice phenology}

Rice in tropical and subtropical Asia is cultivated in irrigated and lowland rainfed. Rice growth duration on transplanted rice and direct seeded rice have short duration (100-120 days), medium duration (120-140 days), and long duration (140-160 days $)^{4}$. Rice phenology normally classified into vegetative, reproductive, maturity, and transplanting ${ }^{5}$. The present study determined rice growth stage into 5 main growth stage such as seedling, tillering, panicle, flowering, and harvesting. Most of rice varieties in study area are short duration rice varieties; however, there are hybrid rice in some sample units in Phichit and Pathum Thani (approximately 75-80 days). The rice phenology under this study can demonstrated as table1.

Table 1. The description of rice phenology.

\begin{tabular}{|l|l|l|}
\hline \multicolumn{1}{|c|}{ Phase } & \multicolumn{1}{|c|}{ Present study } & \multicolumn{1}{c|}{ Name } \\
\hline \multirow{5}{*}{ Vegetative } & Seedling & Germination \\
\cline { 3 - 3 } & & Leaf development \\
\cline { 2 - 3 } & \multirow{2}{*}{ Tillering } & Tillering \\
\cline { 3 - 3 } & & Stem elongation \\
\cline { 3 - 3 } & & Booting \\
\hline \multirow{2}{*}{ Reproductive } & Panicle & Heading \\
\cline { 2 - 3 } & Flowering & Flowering \\
\hline Maturity & & Development of fruit \\
\cline { 3 - 3 } & & Ripening \\
\cline { 2 - 3 } & Harvesting & Senescence \\
\hline Transplanting & & Transplanting, recovery (rice) \\
\hline
\end{tabular}

According to table1, the seedling and tillering stage are vegetative phase which rice develop rice stems structure. The panicle and flowering stage are reproductive phase. The reproductive phase, rice develop panicles/grains. Finally, harvesting stage is maturity phase.

(a) Seedling

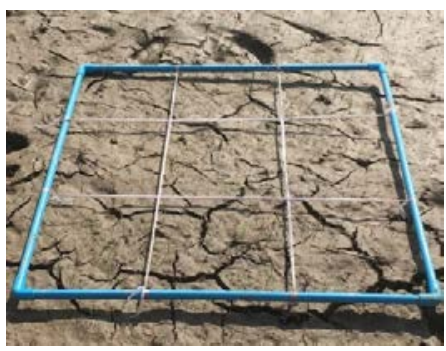

(d) Flowering

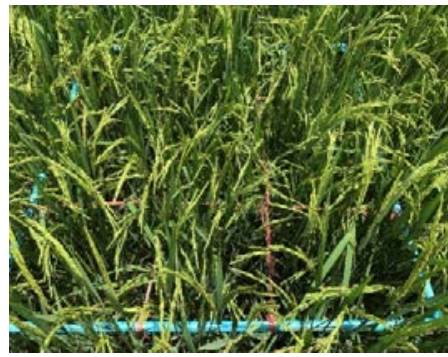

(b) Tillering

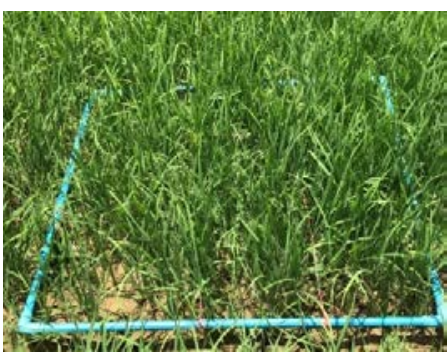

(e) Harvesting (c) Panicle

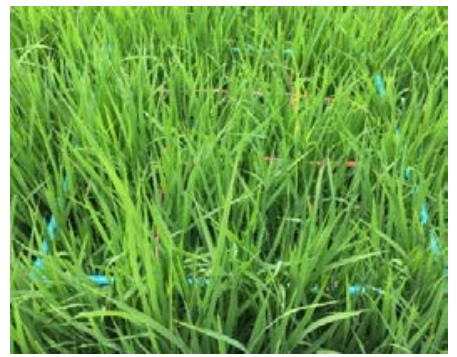

Figure 2. Rice phenological phases in study area in wet season 2017. (a) Seedling, (b) Tillering, (c) Panicle, (d) Flowering, and (e) Harvesting.

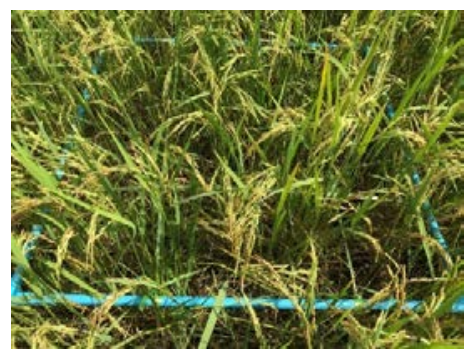


In seedling stage, farmers have several patterns of rice growing such as direct seedling and transplanting pattern. Most farmers soaked rice seeds overnight and then sowing rice seeds directly to water paddy field. The seedling stages have duration approximately 20 days. In tillering stage, rice develop rice leaves 3-4 leaves and 15-20 days after transplanting. The reproductive phase have 35 days duration that rice develop vertical expansion of rice canopy in panicle phase and there are panicle initiation. Normally, rice leaf are index are peaked at heading stage. At heading stage, panicle emerged on the last of rice leaves which is called flag leaf. Then, rice develop their grains in flowering phase.

\subsection{Methodology}

The study develop rice yield estimation by using earth observation data and field survey data. Radar sensor are used because they have main characteristic to penetrate cloud cover which is mainly problem on rice in wet season particularly in Southeast Asian region. In radar sensor, the study analyses Sentinel-1 and related with rice biophysical parameters and analyses. The study determined the several of backscatter coefficient (e.g., sigma, gamma, and beta backscatter coefficient). To achieve which orbit directions and polarizations have high correlate with rice biophysical, the study analyses difference orbit direction (e.g., ascending and descending) and difference polarizations (e.g., VV (transmitted signal in vertical and received in vertical) and VH (transmitted signal in vertical and received in horizontal).

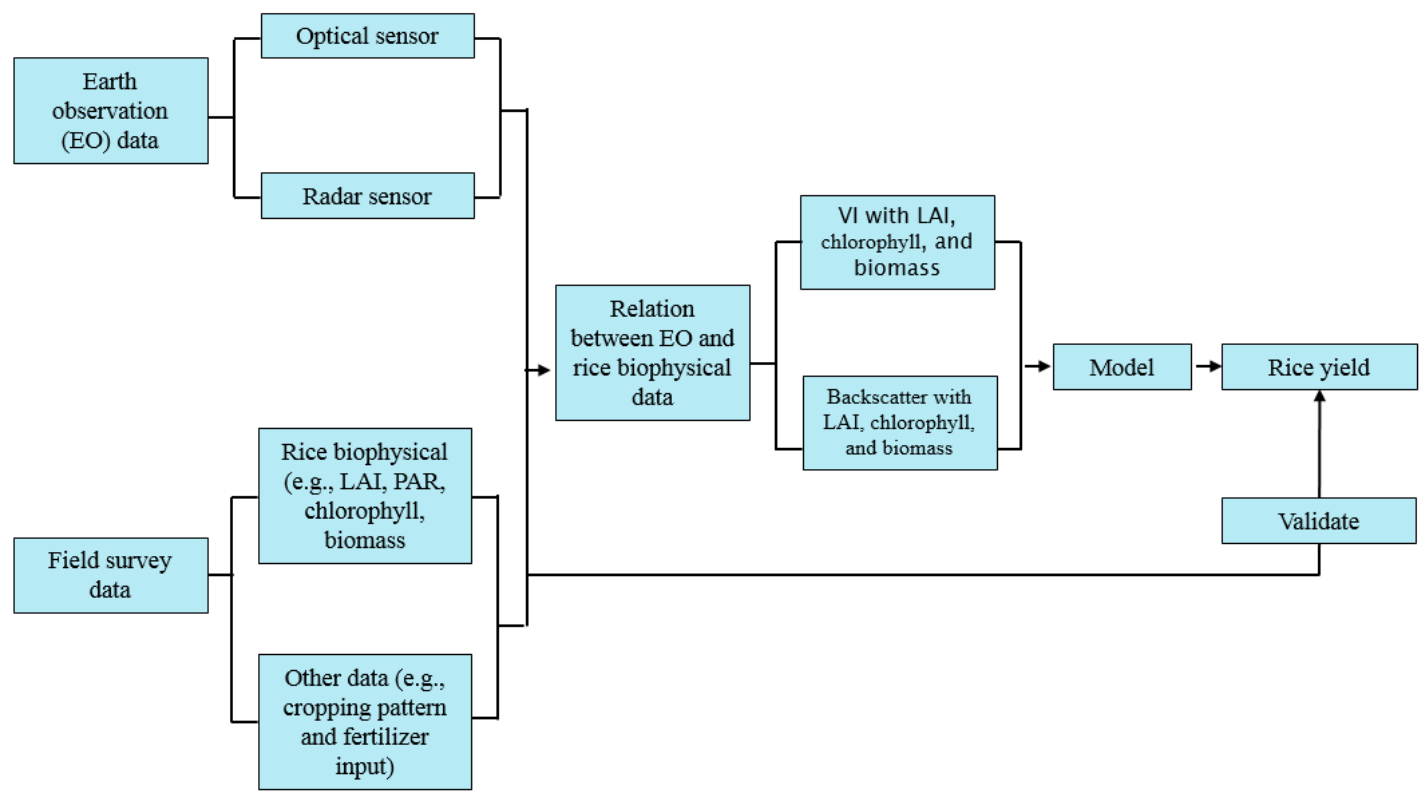

Figure 3. The method of the present study.

\section{DATA}

\subsection{Satellite data}

SAR (Synthethic Aperture Radar) sensor have several products in globally such as RADARSAT-2, COSMO SKYMED, ALOS-2, and Sentinel-1.The SAR sensor have a potential to penetrate cloud cover because it uses microwave waveband and SAR has captured data both day and night operational capabilities. The study adopt Sentinel-1 in single look complex (SLC) and interferometric wide swath (IW) mode. In addition, the study download difference of orbit directions and difference polarizations. 
Table 2. Sentinel-1 characteristics

\begin{tabular}{|c|c|c|c|c|c|c|}
\hline Satellite & $\begin{array}{c}\text { Sensor } \\
\text { Complement }\end{array}$ & Orbit type & Acquisition mode & $\begin{array}{c}\text { Swath } \\
(\mathbf{k m})\end{array}$ & $\begin{array}{c}\begin{array}{c}\text { Spatial } \\
\text { resolution } \\
(\mathbf{m})\end{array} \\
\end{array}$ & Polarization \\
\hline \multirow[t]{4}{*}{$\begin{array}{l}\text { Sentinel-1A } \\
\text { and } \\
\text { Sentinel-1B }\end{array}$} & \multirow[t]{4}{*}{ C-SAR } & \multirow[t]{4}{*}{$\begin{array}{l}\text { Sun- } \\
\text { synchronous } \\
\text { orbit } 12 \text { day } \\
\text { repeat cycle }\end{array}$} & Stripmap (SM) & 80 & $5 \times 5$ & $\begin{array}{l}\mathrm{HH}, \mathrm{VV}, \\
\mathrm{HV}, \mathrm{VH}, \\
\mathrm{HH} / \mathrm{HV}, \\
\mathrm{VV} / \mathrm{VH}\end{array}$ \\
\hline & & & $\begin{array}{l}\text { Interferometric Wide } \\
\text { Swath (IW) }\end{array}$ & 250 & $5 \times 20$ & \\
\hline & & & $\begin{array}{l}\text { Extra Wide Swath } \\
(\mathrm{EW})\end{array}$ & 400 & $25 \times 100$ & \\
\hline & & & $\begin{array}{l}\text { Elevation Notch (EN) } \\
\text { and azimuth notch } \\
\text { (AN) }\end{array}$ & & $5 \times 20$ & \\
\hline
\end{tabular}

\subsection{Rice biophysical data}

In field survey, the study collected important of rice biophysical parameters such as water depth, rice density, rice height, leaf area index (LAI), fraction of absorbed photosynthesis (FAPAR), chlorophyll content, wet and dry biomass, rice yield. In several rice growth stage, the study collect various rice biophysical as demonstrated on table 2 .

Table 3. Rice biophysical parameters in each growth stage

\begin{tabular}{|c|c|c|c|c|c|c|c|c|c|c|c|}
\hline \multirow{2}{*}{$\begin{array}{c}\text { Growth } \\
\text { phase }\end{array}$} & \multirow{2}{*}{$\begin{array}{c}\text { Rice } \\
\text { density }\end{array}$} & \multirow{2}{*}{$\begin{array}{l}\text { Water } \\
\text { depth }\end{array}$} & \multirow{2}{*}{$\begin{array}{c}\text { Rice } \\
\text { height }\end{array}$} & \multirow{2}{*}{$\begin{array}{l}\text { Panicle } \\
\text { length }\end{array}$} & \multicolumn{2}{|c|}{ PAR } & \multirow[t]{2}{*}{ LAI } & \multirow{2}{*}{$\begin{array}{l}\text { Chlorophyll } \\
\text { content }\end{array}$} & \multirow[t]{2}{*}{ Biomass } & \multirow[t]{2}{*}{ Yield } & \multirow[t]{2}{*}{ Humidity } \\
\hline & & & & & Above & Below & & & & & \\
\hline Seedling & $\sqrt{ }$ & $\sqrt{ }$ & & & & & & $\sqrt{ }$ & & & \\
\hline Tillering & $\sqrt{ }$ & $\sqrt{ }$ & $\sqrt{ }$ & & $\sqrt{ }$ & $\sqrt{ }$ & $\sqrt{ }$ & $\sqrt{ }$ & & & \\
\hline Panicle & $\sqrt{ }$ & $\sqrt{ }$ & $\sqrt{ }$ & $\sqrt{ }$ & $\sqrt{ }$ & $\sqrt{ }$ & $\sqrt{ }$ & $\sqrt{ }$ & $\sqrt{ }$ & & \\
\hline Flowering & $\sqrt{ }$ & $\sqrt{ }$ & $\sqrt{ }$ & $\sqrt{ }$ & $\sqrt{ }$ & $\sqrt{ }$ & $\sqrt{ }$ & $\sqrt{ }$ & $\sqrt{ }$ & & \\
\hline Harvesting & $\sqrt{ }$ & $\sqrt{ }$ & $\sqrt{ }$ & $\sqrt{ }$ & $\sqrt{ }$ & $\sqrt{ }$ & $\sqrt{ }$ & $\sqrt{ }$ & $\sqrt{ }$ & $\sqrt{ }$ & $\sqrt{ }$ \\
\hline
\end{tabular}

In the field survey, the study put sample frame with size $1 \mathrm{~m}$. x $1 \mathrm{~m}$. at 4 corners of sample units and collected rice biophysical parameters.

\subsection{Field survey date}

Rice in wet season began in May to October of year; however, the exactly planting date is depend on sufficient of water capability. In general, the involved government discuss and summary the exactly date to farmers before planting period. The planting date depend on the availability of water for crop requirement. The study seek the excellent sample units with nearly planting date (approximately 3-7 days) and the planting date were derived from farmer's interview. The planting date were difference in study area. The planting date began 3 May to 24 May 2017. The average of planting date in Phichit, Ang Thong, and Pathum Thani were 11 May, 22 May, and 8 May 2017, respectively. In Phichit, which have both irrigated rice area and rainfed rice area, the planting date were a bit difference. For example, the irrigated rice area and rainfed rice areas in Phichit are 10 May 2017 and 13 May 2017, respectively. The research attempt to download satellite data both in optical sensor and radar sensor nearly field survey date to achieve representative data of sample units. 
Table 4. Field survey date and acquisition date of satellite data

\begin{tabular}{|l|l|l|l|l|}
\hline \multirow{2}{*}{$\begin{array}{c}\text { Growth } \\
\text { phase }\end{array}$} & \multicolumn{1}{|c|}{ Survey date } & \multicolumn{3}{c|}{ Satellite date } \\
\cline { 3 - 5 } & & \multicolumn{1}{c|}{ Landsat 8 } & \multicolumn{2}{c|}{ Sentinel-1 } \\
\cline { 3 - 5 } & & & Ascending & Descending \\
\hline Seedling & 20 May - 7 June 2017 & $\begin{array}{l}\text { 24 May and } \\
\text { 2 June 2017 }\end{array}$ & & 26 May 2017 \\
\hline Tillering & 26 June - 10 July 2017 & 25 June and 4 July 2017 & 27 June 2017 & 1 July 2017 \\
\hline Panicle & 19-30 July 2017 & 27 July 2017 & 21 July 2017 & 25 July 2017 \\
\hline Flowering & 1- 16 August 2017 & 5 and 12 August 2017 & 2 August 2017 & 6 August 2017 \\
\hline Harvesting & 9 August - 3 Sept 2017 & 21 and 28 August 2017 & 26 August2017 & 30August2017 \\
\hline
\end{tabular}

\section{PRELIMINARY RESULTS}

\subsection{Rice varieties}

There are 10 main non-sensitive rice varieties in study area with 2 main rice varieties are hybrid rice (e.g., 13A and Chito varieties). The advantages of hybrid rice are increase yields, competitive with weeds, and resistance to disease and insects. Both of hybrid rice varieties planted in Phichit province and located in rainfed rice areas. In study area, RD41 is favourite for planting during wet season (9 sample units) and all of RD41 rice varieties planted in irrigated rice areas.

\subsection{Rice biophysical parameters}

\subsubsection{Water depth}

The average of water depth varied in growing period and there are highest of water depth in tillering stage. The result revealed that water depth in seedling, tillering, panicle, flowering, and harvesting stage are 4.04, 5.19, 4.58, 4.68, and 1.59 $\mathrm{cm}$, respectively.

\subsubsection{Rice density}

Rice density cluster in seedling and tillering stage; however, some rice stems dies in panicle stage. The range of rice density in these two stage are 360-415 stems $\mathrm{m}^{-2}$.

\subsubsection{LAI}

The study measured LAI in 4 rice growth stages by using AccuPAR LP-80 ceptometer (Decagon, USA) ${ }^{6,7}$. The LAI measured above rice canopy with 5 times per sample plot to calculate the average of LAI in each sample unit. In addition, the study also consider the difference of LAI among rice varieties and irrigation system.

(a) LAI in Phichit

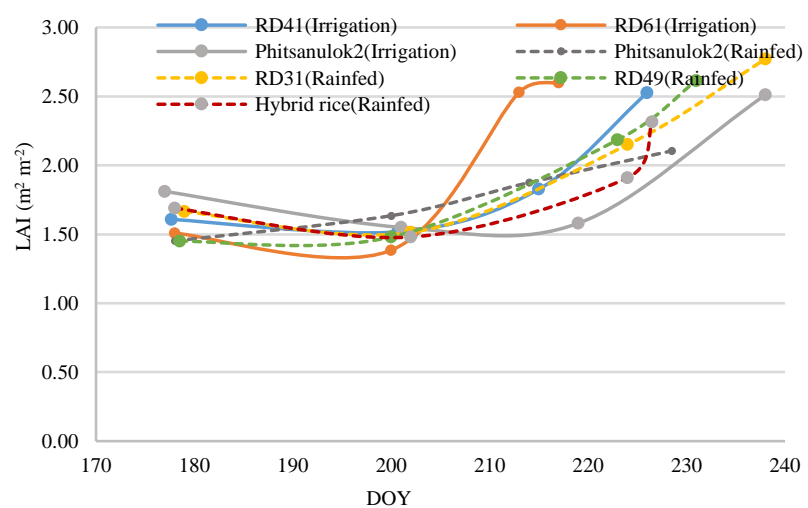

(b) LAI in Ang Thong

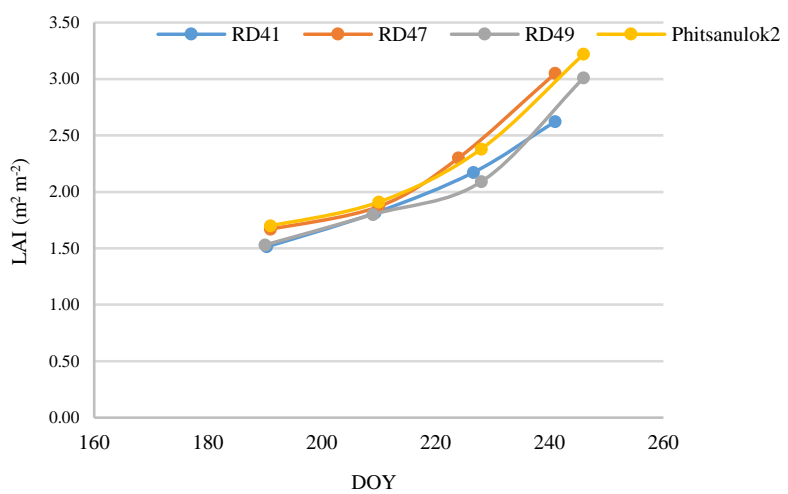


(c) LAI in Pathum Thani

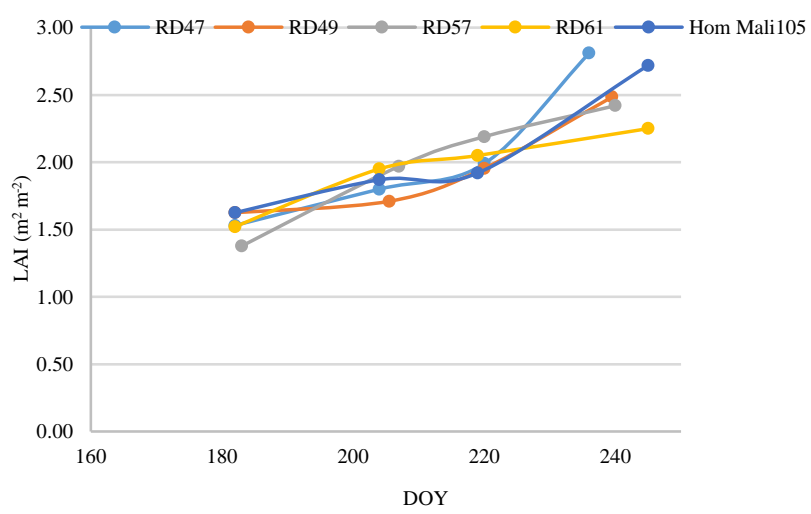

Figure 4. The LAI in study area. (a) LAI in Phichit, (b) LAI in Ang Thong, and (c) LAI in Pathum Thani.

\subsubsection{Chlorophyll content}

Chlorophyll content are highly related with the development of rice leaves or in terms of leaf area index ${ }^{8,9}$. The study measured the amount of chlorophyll content in rice leaves by using chlorophyll meter (MultispecQ v.1). There are 3-4 times measurement in each sample plot and the measurement attempts to measure the excellent representative of rice leaves.

(a) Chlorophyll content in Phichit

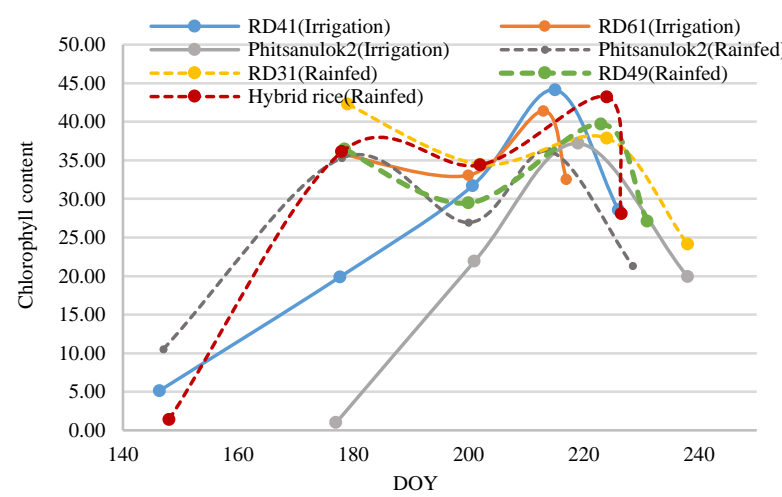

(c) Chlorophyll content in Pathum Thani

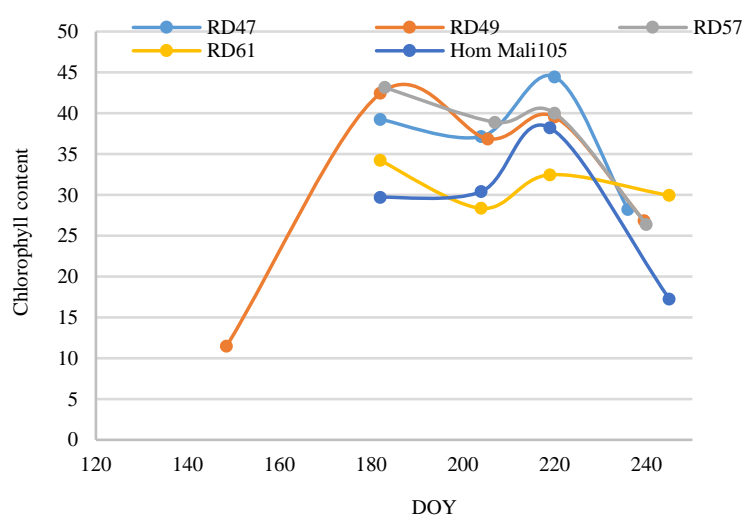

(b) Chlorophyll content in Ang Thong

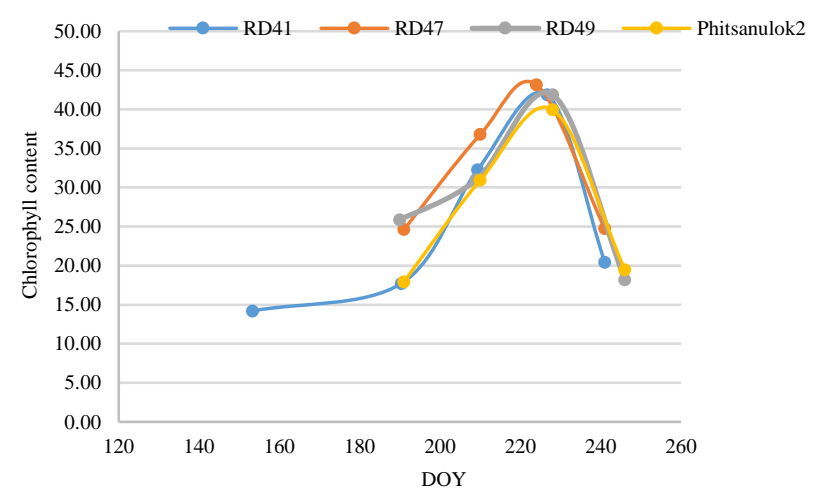

Figure 5. The LAI in study area. (a) LAI in Phichit, (b) LAI in Ang Thong, and (c) LAI in Pathum Thani. 


\subsubsection{Biomass}

Biomass is relevant with rice production and normally biomass classified into wet and dry biomass ${ }^{10}$. After counting rice stems in sample plot, the field survey plunking rice stems approximately $2 \%$ of total rice stems in sample frame. Then, the study weight wet rice stems by an electronic scale (e.g. rice with roots, rice without roots, stems, and panicles). Then, rice stems without roots were baked at $80 \mathrm{C}$ for $2^{\circ}$ days to gain real weight of rice stems and panicle without moisture or release constant of rice weight.

(a) Wet and dry biomass in Phichit
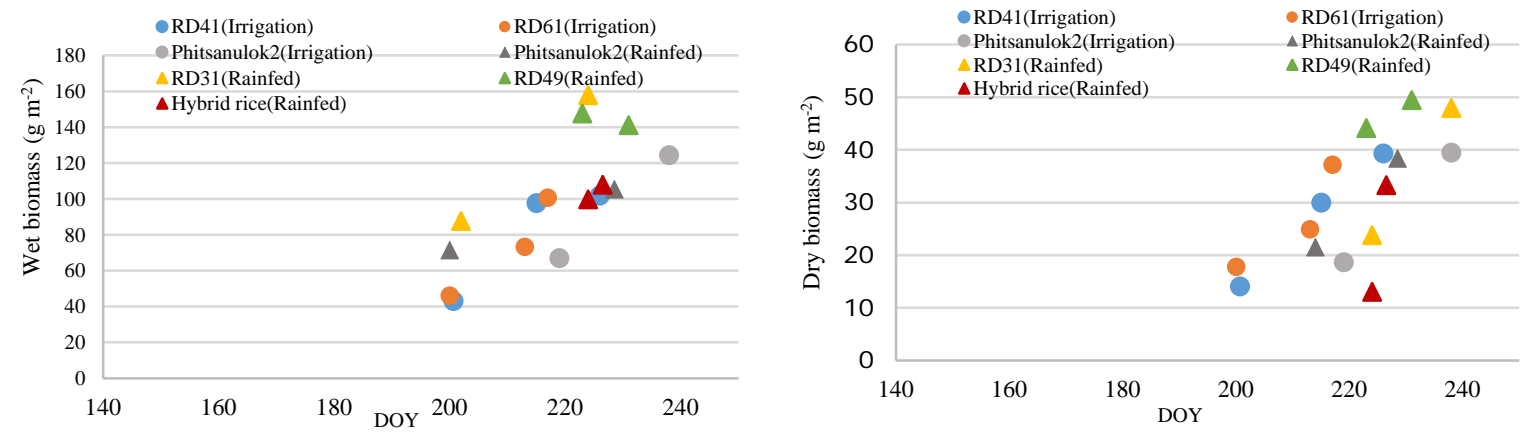

(b) Wet and dry biomass in Ang Thong
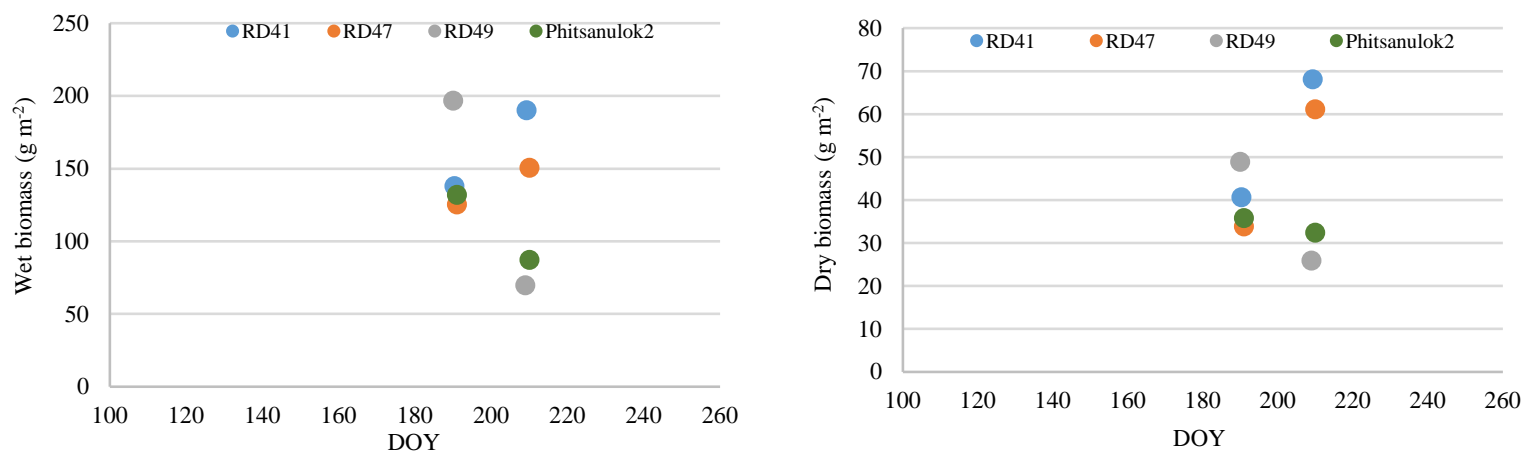

(c) Wet and dry biomass in Pathum Thani
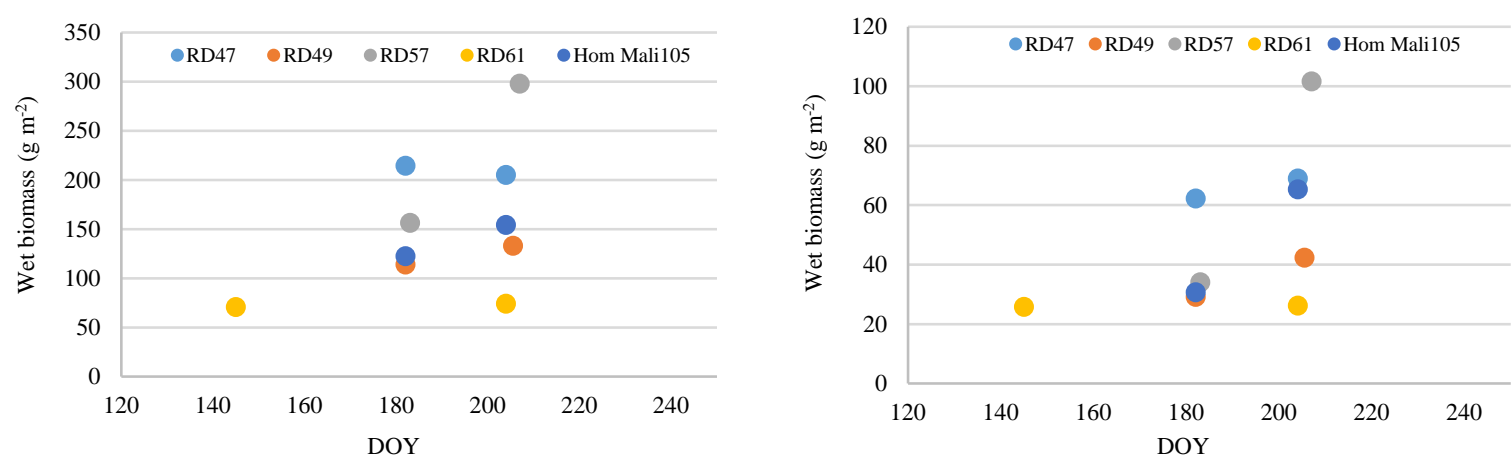

Figure 6. Wet and dry biomass. (a) Wet and dry biomass in Phichit, (b) Wet and dry biomass in Ang Thong, and (c) Wet and dry biomass in Pathum Thani. 


\subsubsection{Rice yield}

The study cut and weighted rice stems in sample frame by using Crop Cutting Experiment (CCE) method. The CCE method have two samples in one sample units which is called A and B. The method cut rice stems and weight rice grains then calculate rice yield and rice humidity.

\subsection{The backscatter coefficient}

SAR satellite data require radiometric correction to convert backscatter cross-section to backscatter coefficient ${ }^{11,12,13,14}$. The study analyses the difference orbit direction (e.g., ascending and descending) and difference polarizations (e.g., VV and VH) ${ }^{15}$.

\section{(a) Seedling}

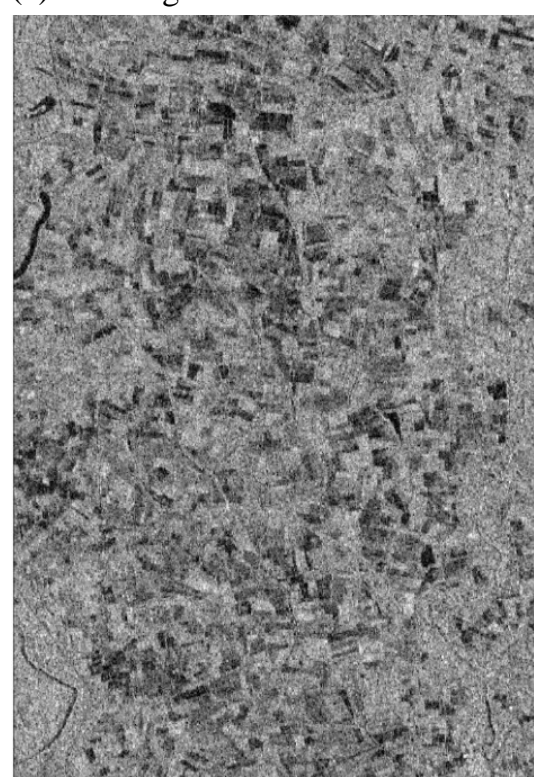

(d) Flowering

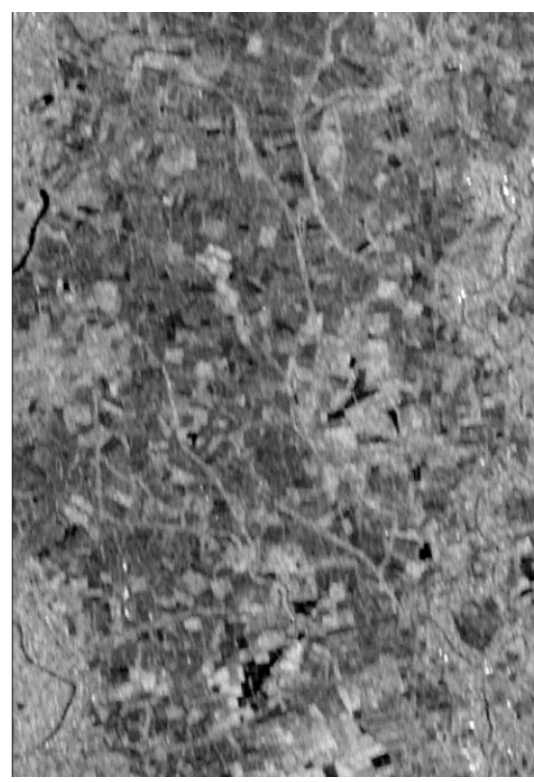

(b) Tillering

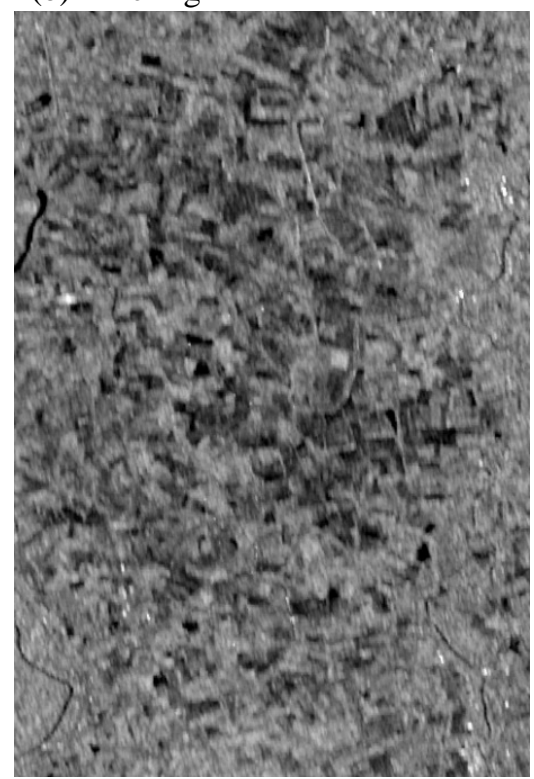

(e) Harvesting

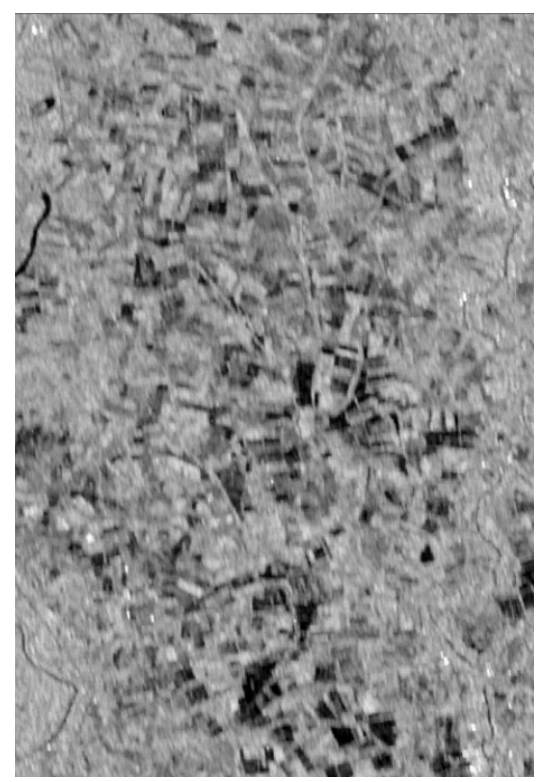

(c) Panicle

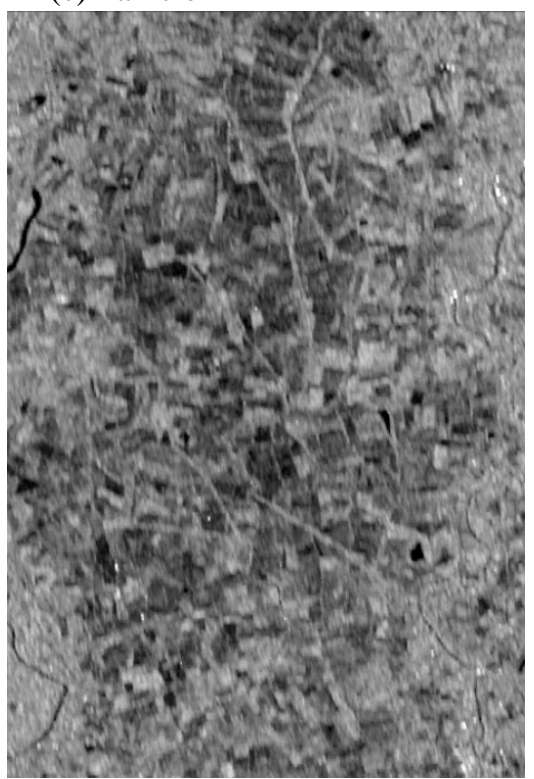

Figure7. The sigma naught (dB) backscatter coefficient in ascending mode and VV polarization in Phichit. (a) Seedling, (b) Tillering, (c) Panicle, (d) Flowering, and (e) Harvesting. 

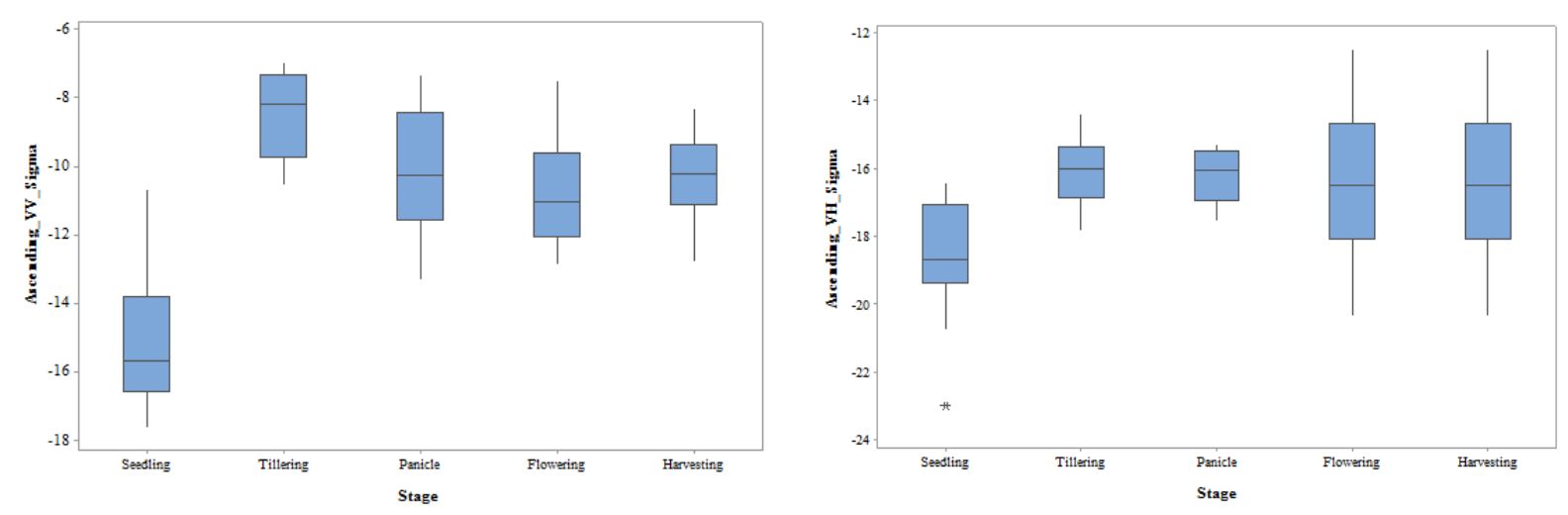

Figure 8. The backscatter coefficient (dB) in VV and VH polarization in Phichit.

The result revealed that there are low of backscatter coefficient in seedling stage because there are water in paddy field and then backscatter coefficient tend to increase when rice develop their structure. The sigma naught (dB) backscatter of VV polarization have low value when compared with VH polarization. The average of sigma backscatter coefficient in ascending and VV polarization in seedling, tillering, panicle, flowering, and harvesting stage are -15.195, -8.460, -10.141, -10.797, and -10.242, respectively. While the average of sigma backscatter coefficient in ascending and VH polarization in seedling, tillering, panicle, flowering, and harvesting are $-18.636,-16.101,-16.081,-16.216$, and -16.372 , respectively.

\section{CONCLUSIONS}

The field experimental explored rice development in 5 main growth stages and capture the important of rice biophysical parameters. These dataset demonstrated at least verification between the difference sites and rice growth stages. Using Sentinel-1 radar have strong potential to estimate rice structure parameters (e.g., LAI and biomass). Then, the next study will compare with optical sensor ${ }^{16,17}$ based with radar retrievals. Finally, the remote sensing will derived rice biophysical parameters will use to stimulate rice crop growth model (ORYZA 2000) to predict rice yield. Then the yield result validate with ground data and compare the accuracy with government statistical data in sub-district and district level.

\section{REFERENCES}

[1] FAOSTAT. (2010). Statistical database of the Food and Agriculture Organization of the United Nations.

[2] FAO. (2017). Rice Market Monitor (Vol.20). https://doi.org/10.1016/j.knee.2017.11.005.

[3] FAO. (2000). Bridging the Rice Yield Gap in the Asia_Pacific Region.

[4] International Rice Research Institute (IRR). (n.d.). Important Management Factors By Growth Stage. Retrieved April 1, 2018, from http://knowledgebank.irri.org/decision-tools/growth-stages-and-important-management-factors.

[5] Kuenzer, C., \& Knauer, K. (2013). Remote Sensing of rice crop areas. International Journal of Remote Sensing, 34(6), 2101-2139.

[6] Cable, J.W., Kovacs, J.M., Shang, J., \& Jiao, X. (2014). Multi-temporal polarimetric RADARSAT-2 for land cover monitoring in Northeastern Ontario, Canada. Remote Sensing, 6(3), 2372-2392.

[7] Behera, S.K., Srivastava, P., Pathre, U.V.., \& Tuli, R. 92010). An Indirect method of estimating leaf area index in Jatropha curcas L. using LAI-2000 Plant Canopy Analyzer. Agricultural and Forest Meteorology, 150 (2), 307-311. 
[8] Asai, H., Samson, B.K., Stephan, H.M., Songyikhangsuthor, K., Homma, K., Homma, K., Kiyono, Y., Horie, T. (2009). Biochar amendment techniques for upland rice production in Northern Laos. 1. Soil physical properties, leaf SPAD, and grain yield. Field Crops Research, 111(1-2), 81-84.

[9] le Maire, G., Francois, C., Soudani, K., Berveiller, D., Pontailer, J.Y., Breda, N., Dufrene, E. (2008). Calibration and validation of hyperspectral indices for the estimation of broadleaved forest leaf chlorophyll content, leaf mass per area, leaf area index and leaf canopy biomass. Remote Sensing of Environment, 112(10), 3846-3864.

[10] Marshall, M., \& Thenkabail, P. (2015). Developing in situ non-destructive estimates of crop biomass to address issues of scale in remote sensing. Remote Sensing, 7(1), 808-835.

[11] Bouvet, A., Le Toan, T., \& Dao, N.L. (2014). Estimation of agricultural and biophysical parameters of rice field in Vietnam using X-band dual-polarization SAR. International Geoscience and Remote Sensing Symposium (IGARSS), (1), 1504-1507.

[12] Chen, C.F., Son, N.T., Chen, C. R., Chang, L. Y., \& Chiang, S.H. (2016). Rice crop mapping using Sentinel-1A phenological metrics. International Archives of the Photogrammetry, Remote Sensing and Spatial Information Sciences- ISPRS Archives, 41 (July), 863-865.

[13] Chen, C., Quilang, E.J.P., Alosnos, E.D., \& Finnigan, J. (2011). Rice area mapping, yield, and production forecast for the province of Nueva Ecija using RADARSAT imagery. Canadian Journal of Remote Sensing, 37(1), 1-16.

[14] Inoue, Y., Sakaiya, E., \& Wang, C. (2014). Capability of C-band backscattering coefficients from high-resolution satellite SAR sensors to assess biophysical variables in paddy rice. Remote Sensing of Environment, 140, $257-266$.

[15] Claudia Kuenzer \& Kim Knauer. (2013) Remote Sensing of rice crop areas, International Journal of Remote Sensing, 34(6), 2101-2139.

[16] Boschetti, M., Busetto, L., Manfron, G., Laborte, A., Asilo, S. Pazhanivelan, S., \& Nelson, A. (2017). PhenoRice: A method of automatic extraction of spatio-temporal information on rice crop using satellite data time series. Remote Sensing of Environment, 194, 347-365.

[17] Bolton, D.K., \& Friedl, M.A. (2013). Forecasting crop yield using remotely sensed vegetation indices and crop phenology metrics. Agricultural and Forest Meteorology, 179, 74-84. 